\title{
LOW COST INTELLIGENT BRAKING SYSTEM
}

\author{
Aman Dubey, Om Rana, Ikhlas Mukhtar Kalkati, Antim Dev Mishra, Dr. Arti Vaish \\ E-Mail Id: artivaish@ansaluniversity.edu.in \\ Department of Electronics and Communication Engineering, Ansal University, Gurgaon, India
}

\begin{abstract}
The general public, policymakers and the automobile industry have developed a growing amount of interest in automotive safety. It is more than explained by the figures on road collisions, where around 1 a year. Thanks to road traffic collisions 2 million people die. This paper introduces a cost-effective crash warning system concept for low-budget cars. Rear-end crashes are typical crash situations, and driver fatigue is a major cause of such incidents and therefore does not respond on time. No security program is a substitution for the most critical safety device of any driver's car. Many vehicle manufactures now use revolutionary technology for a day to help warn drivers to stop crashes and reduce possible impact speed when a collision cannot be stopped. Another such feature is Collision Warning with Automatic Braking where the area in front of the car is constantly tracked with the aid of the long-range sensor and driver is alert in the case of a collision and with the brake assist for collisions with other cars, both driving and stationary. Additionally, if the driver fails to respond given the warning and the potential collision is considered inevitable; brakes are automatically applied to stop the vehicle. This helps to reduce the level of effect and therefore the chance of repercussions. Finally, it was discussed how, using traffic incident data, the utility of these programs can be measured from the real- life safety viewpoint.
\end{abstract}

Keywords: Crash, Arduino Ultrasonic System, Automatic Braking.

\section{INTRODUCTION}

The Automatic Braking Collision Warning system is a mix of many innovations. Over the years, vehicle safety has acquired a growing attention from the general public, governments and the automobile industry. Increasing demand from the general population, governments and the automotive market. An effective means of making ongoing progress in the development of safety is a working cycle focused on real-world scenarios and input on the production of this knowledge. This working approach was found to be very successful for the production of passive protection. This research extends this cycle of working towards the production of modern active protection systems. Strong safety programs require a broader field of research and success targets, thereby extending to incident of injuries next to injury defence and adversary vehicle next to host car. The aim of this paper is to address some of the latest innovations in active protection and put them in perspective. Using blinking LED and LCD monitor, the identification of collisions is achieved by using the Ultrasonic sensor and the Stop signal. Braking is achieved by means of a servo motor attached to a parking brake lever to ensure maximum braking power and minimum braking time. Electromechanical actuation by means of mechanical actuator which makes the action extremely fast, thus ensuring safety braking. Prime mover control is cutoff by means of a relay switch to reduce power wastage and split wear. All these devices are operated using Arduino Super 2560 which is a programmed microcontroller to perform the specified function.

\section{LITERATURE SURVEY}

Integrated protection systems can be commonly broken down into two categories:

\subsection{Crash Avoidance}

Manual braking avoids crash in this system but with this form of system the driver will not be warned. In fact in the case of radars or lasers, there is a very high risk of misinterpreting the signals. So this type of automatic braking isn't so successful.

\subsection{Collision Avoidance Program}

The sensors sense collision possibilities in this program but do not take prompt action. The driver may receive a warning in the form of a signal or a voice call. The device determines a safe threshold distance, and if the driver fails to respond even when the vehicle reaches the area, then only brakes are automatically applied. But if the signals are misinterpreted, there is no question because the brake decision is left to the driver and the brakes are applied automatically only in most emergency situations.

Various innovative steering assistive technologies:

\subsection{Emergency Brake Assist (EBA)}

This is a common term for an automotive braking technology which in an emergency situation increases the braking pressure. Daimler-Benz and TRW / LucasVarity jointly developed the original design. Work at the Mercedes-Benz driving simulator in Berlin in 1992 showed that in emergency circumstances more than 90 per cent of drivers struggle to stop with adequate power. Through measuring the speed and force by which the brake pedal is driven, the system determines if the driver is trying to perform an emergency stop, and if the brake pedal is not completely applied, the system overrides and automatically stops before the Anti-lock Braking System (ABS) takes over to protect the wheels from locking up. 


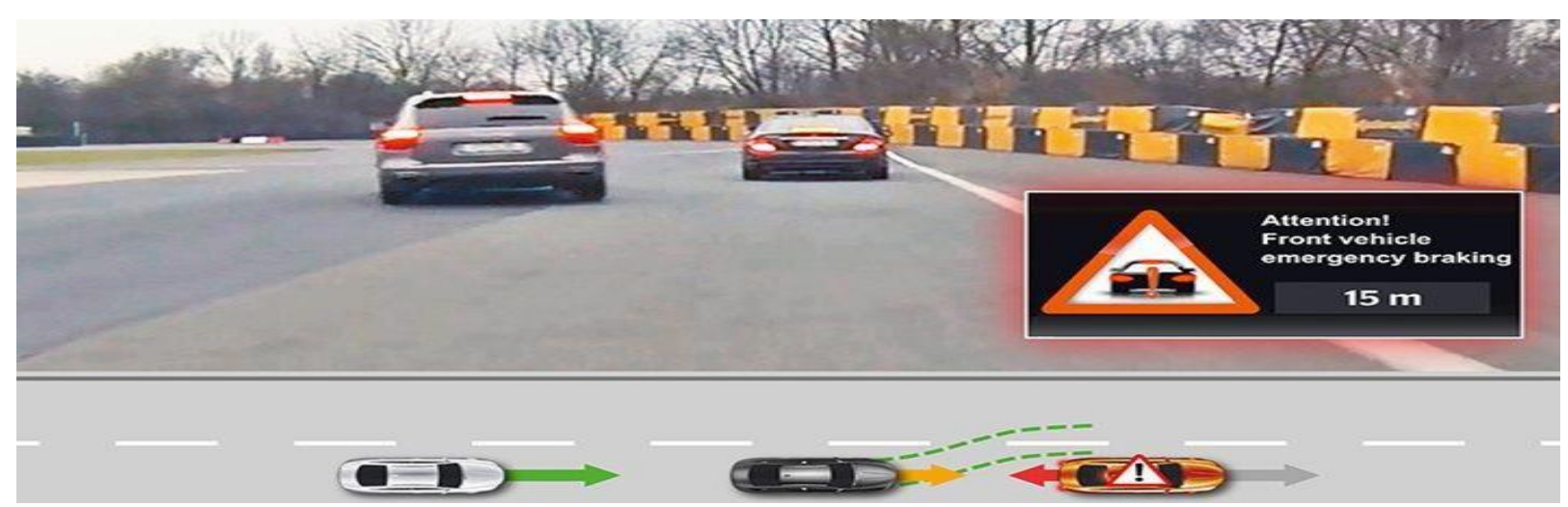

Fig. 2.1 Electronic Brake Assist

\subsection{Electronic Brake Force Distribution (EBD or EBFD)}

It is an automotive brake system that dynamically adjusts the amount of force applied to each of the brakes of a car, depending on ground conditions, distance, charging, etc. EBD should also add more or less brake pressure to each wheel in tandem with anti-lock braking systems to increase the stopping power while retaining vehicle stability. The front end usually bears the most weight, and EBD distributes less braking power to the rear brakes to keep the rear brakes from locking up and creating a skid. In certain systems, before the weight shift effects are evident, EBD distributes more braking energy at the rear brakes during initial brake operation.

\section{Electronic Brake-force Distribution (EBD)}

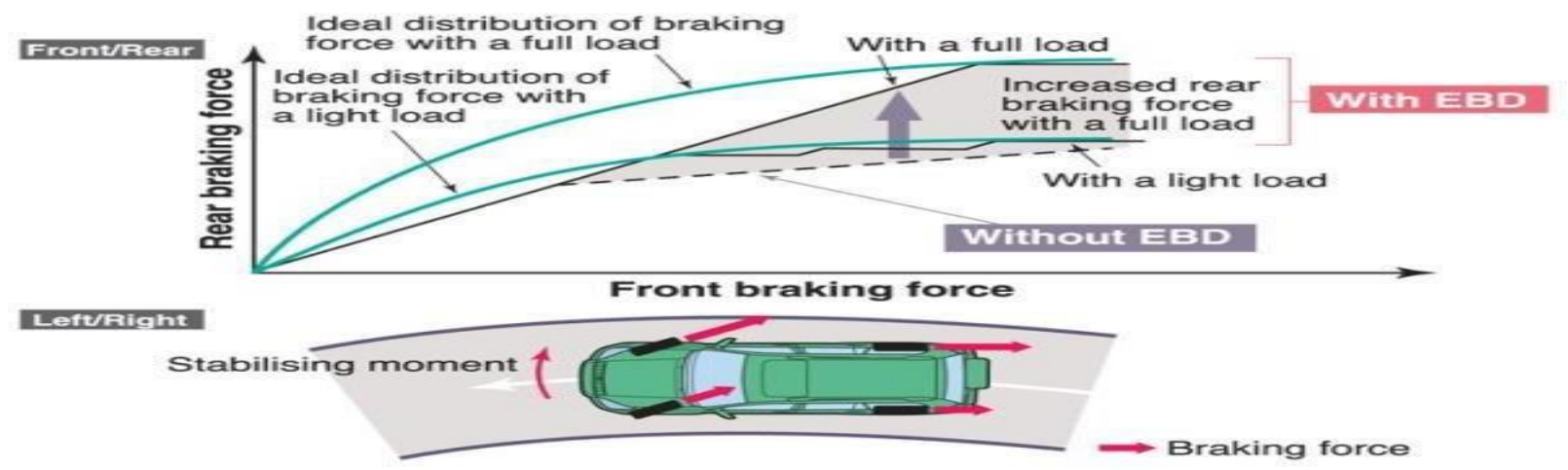

Fig. 2.2 Electronic Brake Force Distribution

\subsection{Automated Emergency Braking (AEB)}

An automated road vehicle safety device that uses sensors to track the proximity of front-end vehicles and detects situations where the relative velocity and distance between the host and target vehicles indicates an imminent collision. In such a case, emergency braking can be applied automatically to stop the collision, or at least to minimize its damage. A new research estimates that if all vehicles feature the program, injuries will be lowered by up to 27 percent, saving up to 8,000 lives a year.

\subsection{Anti-lock Braking System (ABS)}

It is an automotive safety mechanism that helps the wheels on a motor vehicle to keep tractive contact with the ground surface according to driver feedback when braking, keeping the wheels from locking up (ceasing rotation) and stopping uncontrolled skidding. It is an automatic system that uses the threshold braking and cadence braking concepts that have been used with previous generation braking systems by professional drivers. It does so at a much quicker pace than a driver might do and with better precision. ABS usually provides better vehicle control and reduces stopping distances on dry and slick surfaces; however, ABS can greatly increase the braking distance on loose gravel or snow-covered surfaces, while also enhancing vehicle stability.

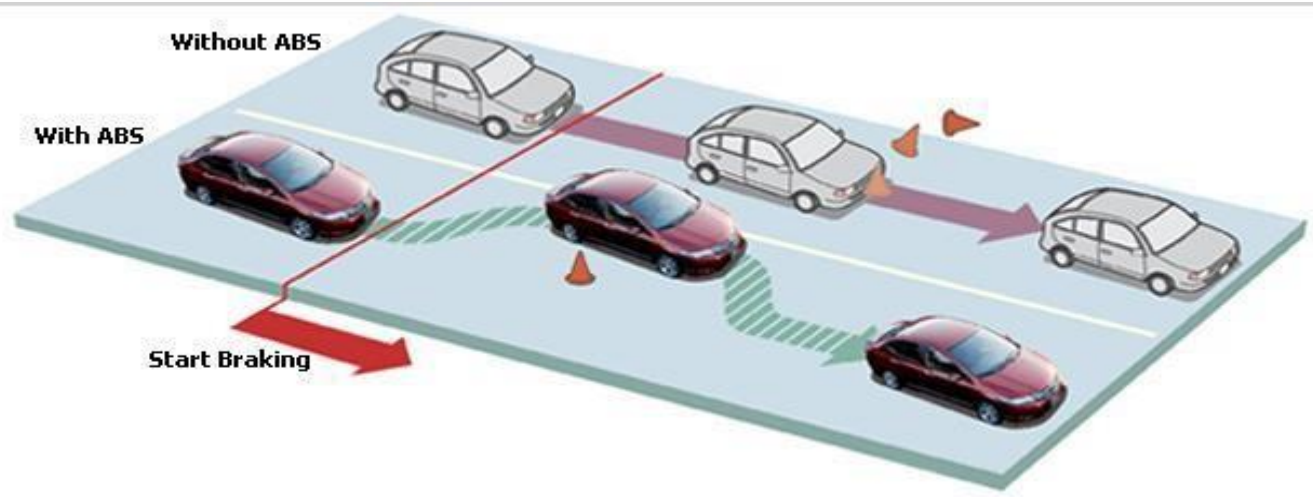

DOI Number: https://doi.org/10.30780/specialissue-ICACCG2020/040

pg. 45 
Fig. 2.3 Anti-Lock Braking System

\section{REQUIREMENT}

According to the road incident statics three million people die in road accidents worldwide in one year. More advanced protection technologies are required in automobiles [2]. One of them is crash warning, along with automatic braking, in which the driver is alert in the case of a crash and brakes are applied and may minimize the number of incidents. The neurological conditions such as driver's fatigue, inattention, and psychiatric problems are the primary causes of fatal accidents. And the driver will be alerted by this device in case of any crash so he can take appropriate measures to prevent incidents.

Annual Estimates of Global Road Accident

$>$ Every year 3 million people die in traffic accidents, an average of 3,287 deaths a day.

$>$ An extra 20-50 million people suffer illnesses or disabilities.

$>$ More than half of all road traffic deaths occur among 15-44 year old young adults.

$>$ Road traffic accidents are ranked as the 9th leading cause of death and represent 2.2per cent of all deaths worldwide.

$>$ Road accidents are the leading cause of death among 15-29 year olds, and the second leading cause of death among 5-14 year olds worldwide.

\subsection{Collision Warning with Automatic Braking System}

$>$ About 400, 000 people under 25 die per year on the highways of the planet, on average more than 1, 000 a day.

$>$ In low and middle-income nations, which have less than half of the world's cars, over 90 per cent of all road accidents occur.

Globally, traffic accidents cost USD 518 billion, losing countries 1-2 per cent of their total GDP.

$>$ Road accidents cost USD 65 billion a year for low- and middle-income nations, increasing the overall amount earned in development assistance.

$>$ If action is taken it is estimated that road traffic accidents will become the fifth leading cause of death by 2030 .

\section{Causes of Fatal Accidents}

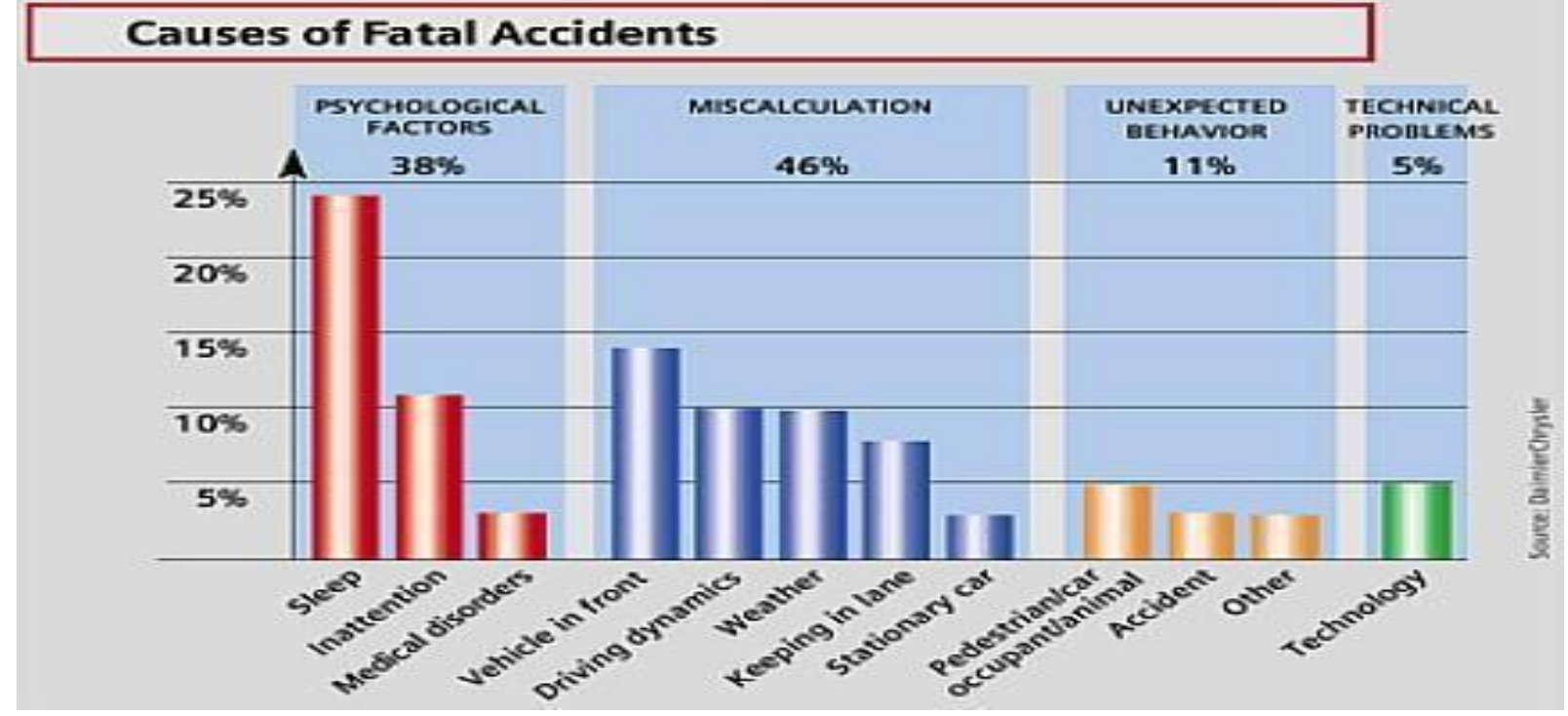

Fig. 3.1 Causes of Fatal Accidents

\section{DEFINITION-PROBLEM}

As applicable to cars, the above-mentioned brake assist systems are incredibly expensive because they compulsorily require a computer for their implementation. Moreover, there is a need for a cost-effective low-end technology or computer that can perform the warning and brake control role with limited use of high-end technology over all such devices. Collision alert with automatic braking system for electric vehicles is a costeffective technology which is also reliable enough to avoid collisions.

\section{SOLUTION}

The Crash alert system with automatic braking system for electric cars is the solution to the problems alluded to above, where the following features have been incorporated:

$>$ Detection of collisions using an Ultrasonic camera.

$>$ Indication of collision using a blinking LED and LCD panel.

$>$ Braking by means of a servomotor attached to the rear brake drum parking cable to ensure maximum braking power and minimum braking time.

$>$ Power is cut off from the prime mover engine to avoid power loss and excessive brake wear. 
ICACCG2020 30-31 July, 2020, Ansal University, Gurgaon, India

International Journal of Technical Research \& Science (Special Issue)

\section{CONSTRUCTION}

The Collision warning system with automatic braking feature for electric vehicles consists of following-

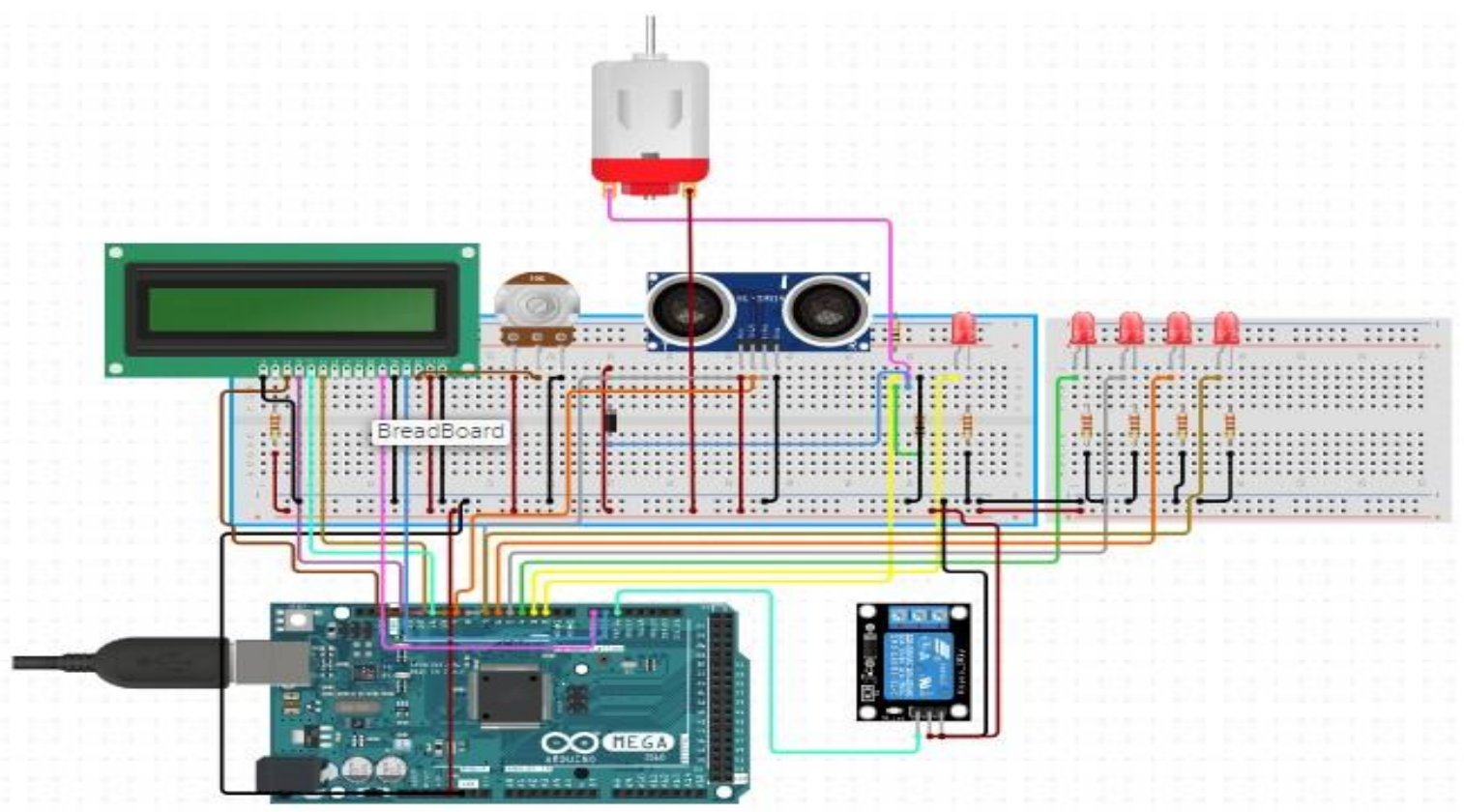

Fig. 6.1 Circuit Diagram

\subsection{Arduino Mega 2560}

The Arduino board consists of an Atmel 8-, 16-or 32-bit AVR microcontroller with complementary modules that enable programming and integration into other circuits. An significant feature of Arduino is its regular connectors, which allow users to connect the CPU board to a number of interchangeable add-on modules known as shields. Most boards are fitted with a 5 volt linear regulator and a $16 \mathrm{MHz}$ crystal oscillator, although some prototypes, such as the LilyPad, operate at $8 \mathrm{MHz}$ and do not use the onboard voltage regulator due to different form factor constraints. The Arduino microcontroller is also pre-programmed with a boot loader that simplifies transferring programs to an on-chip flash memory relative to other tools.

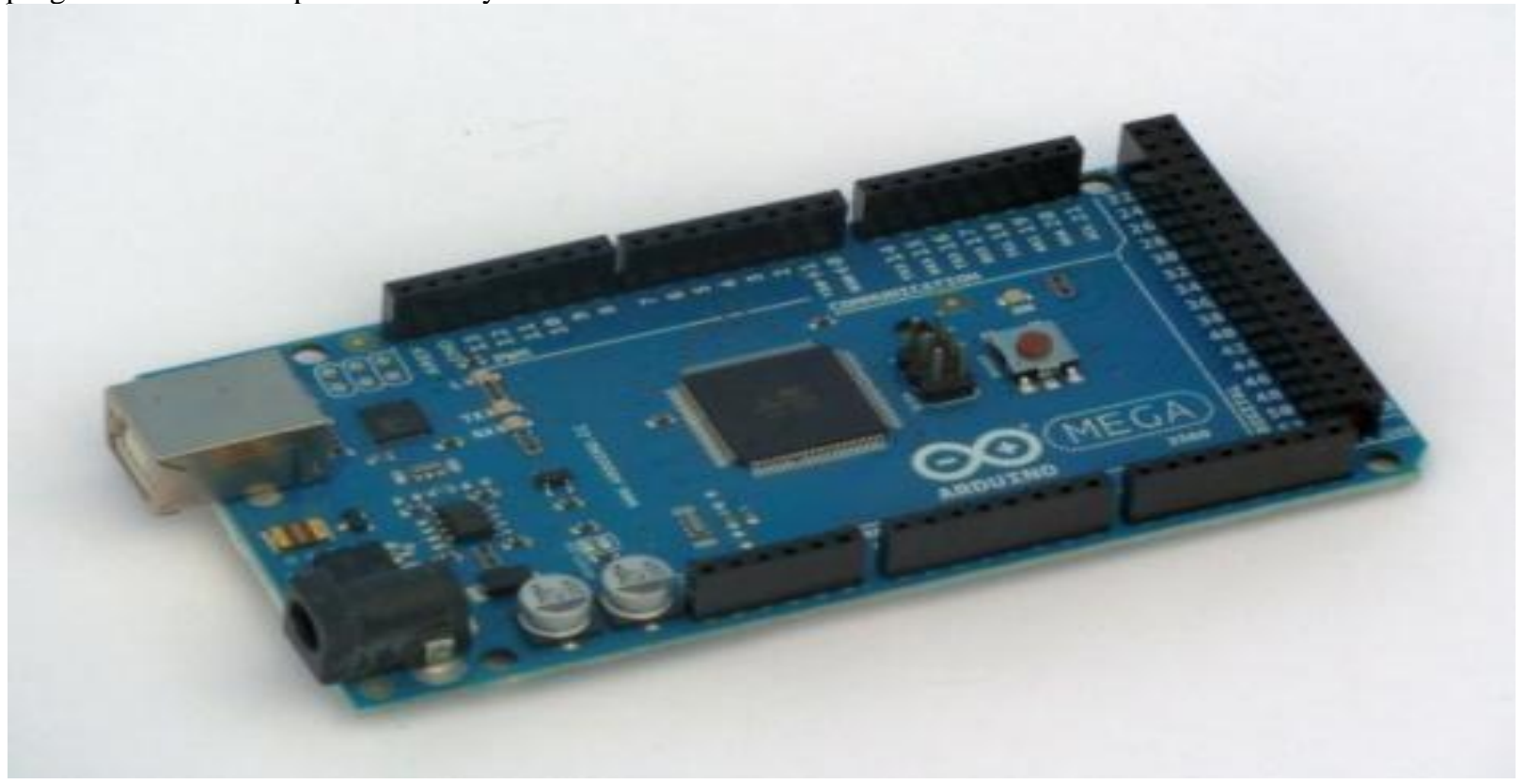

Fig. 6.2 Arduino Mega 256

\subsection{Sensing Process for Collision}

The angle between the car and the barrier is measured using an Ultrasonic sensor. Like radar, lidar and active infrared systems, ultrasound can be used for identification and variety of applications using the flight time concept to measure the distance to an object. Ultrasonic signals are essentially waves of frequencies greater than those which are visible to the human ear, ideal for short to medium range applications at low level. Ultrasonic range module HC-SR04 has $2 \mathrm{~cm}-400 \mathrm{~cm}$ non-contact measurement feature, the range of precision can be up to $3 \mathrm{~mm}$.

The basic principle of work:

$>\quad$ Use an IO stimulus with at least 10us high-level signals. 
ICACCG2020 30-31 July, 2020, Ansal University, Gurgaon, India

International Journal of Technical Research \& Science (Special Issue)

$>$ The module sends $840 \mathrm{kHz}$ automatically and determines that there is a pulse signal back.

$>$ If the pulse returns from a high stage, the time of maximum output IO length is the time from ultrasonic to return.

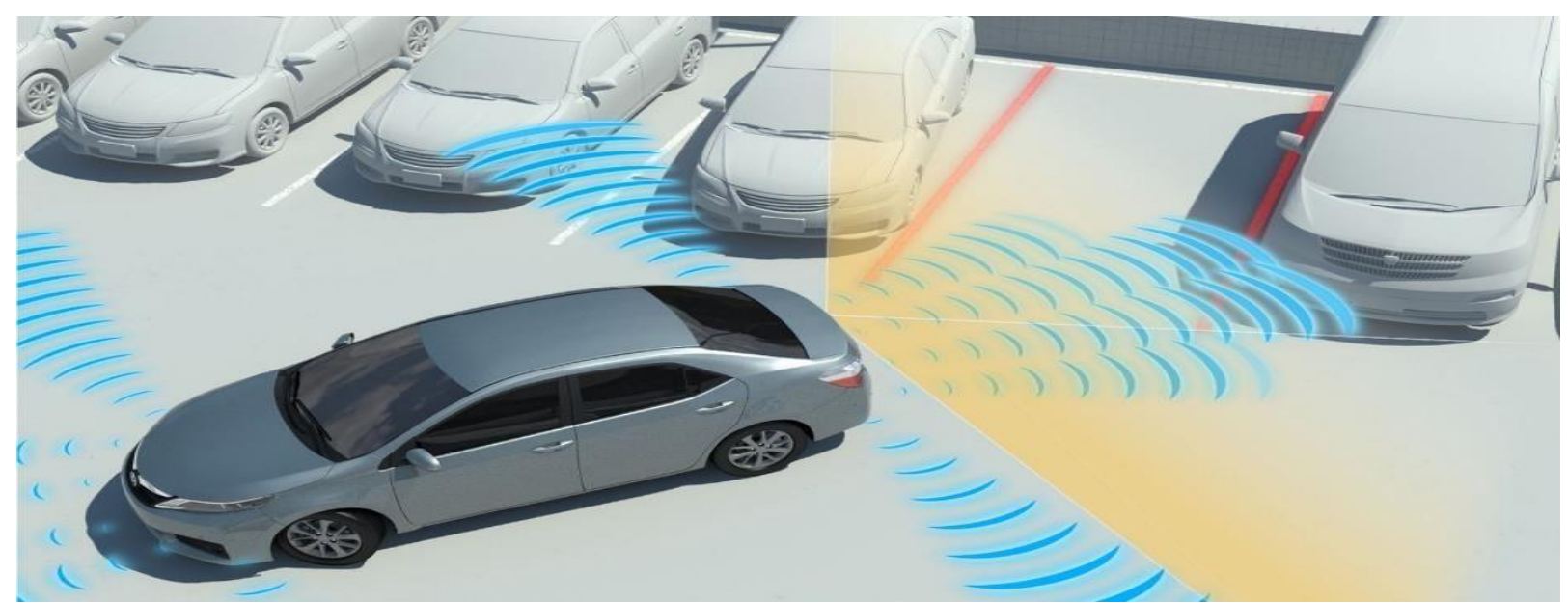

Fig. 6.3 Ultrasonic Sensor in Cars

\subsection{Collision Alert Indicator}

This is an sign or detection device, the light is a red LED light that shines when the speed is too high, along with an LCD monitor, showing the distance between the car and the obstruction by alarming the driver.

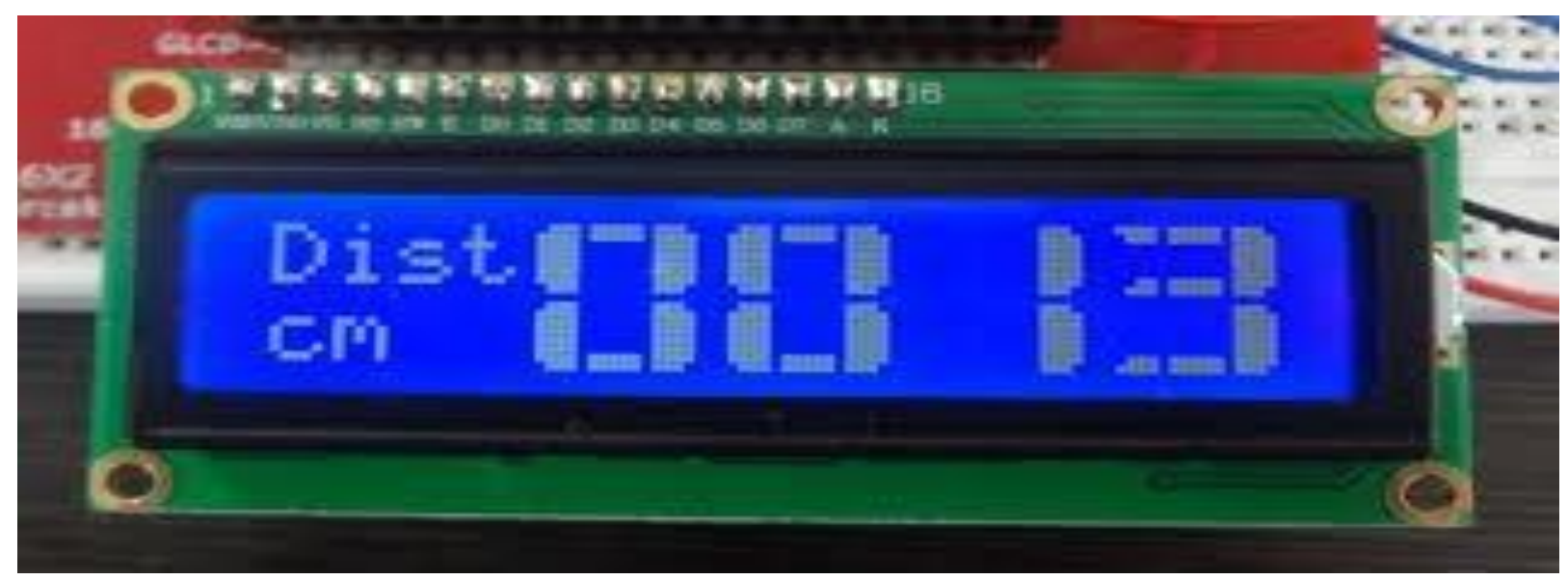

Fig. 6.4 LED'S and LCD Display

\subsection{Electronic Relay}

Relay functions as a mechanism that is switched on and off using a signal. The current state of the relay by the light emitting diode. It can be operated through a digital IO port such as solenoid valves, lights, motors and other high-voltage or high-voltage equipment.

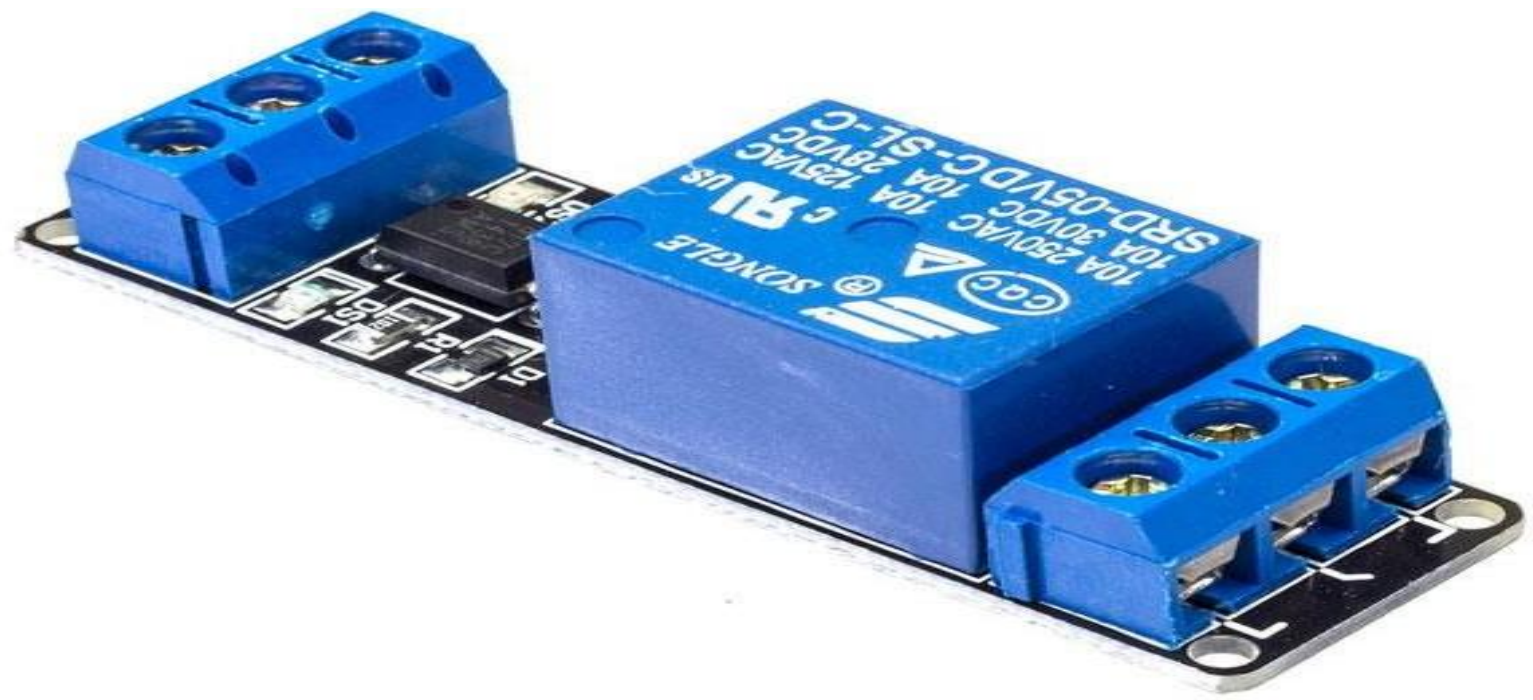

Fig. 6.5 Electronic Relay

DOI Number: https://doi.org/10.30780/specialissue-ICACCG2020/040

Paper Id: IJTRS-ICACCG2020-040

pg. 48 
ICACCG2020 30-31 July, 2020, Ansal University, Gurgaon, India

International Journal of Technical Research \& Science (Special Issue)

\subsection{Braking Mechanism}

The brake is triggered by means of a servo motor. The servo motor arm is attached to the brake pedal. When the servo motor arm rotates, the brake pedal is triggered and the brake is applied.

\subsection{Working Mechanism}

When the distance between the car and the barrier falls beyond the acceptable limits of the ultrasonic sensors, the Arduino transmits the feedback signal to the servo motor and the relay switch, as well as to the LCD panel and the LED flashers. The function of the servo motor is the angle at which it has to spin, and the relay control is to shut off the signal by which the unit $i$. $i$. The prime mover connected to it is turned off. The difference between the cars and the barrier is seen in the LCD monitor with red color LED flashers switched on warning the driver of the collision.

\subsection{Sensor Positioning}

The location of the sensor varies depending on the scale of the car. Generally, for a passenger car, we need to use one ultrasonic sensor in the front, which is mounted to the bumper in the centre.

\subsection{Braking}

The braking of a car relies on the continuous friction between the tires and the ground surface. Brakes operate on the following concept to stop the car: [2] "The kinetic energy due to car motion is dissipated in the form of heat energy due to friction between moving parts (rocket or tire drum) and stationary parts of the vehicle (brake shoes)." The heat energy produced by the brake application is dissipated into the air. The brakes work more efficiently when deployed in such a manner that the wheels do not lock entirely but continue to roll without sliding on the surface of the ground.

Hydraulic brakes are widely found in vehicles. Concept Hydraulic brakes are based on the principle of Pascal's law, which says that "energy at a point in a fluid is equal in all directions in space." Due to this rule, as the friction is applied to the gas, it moves uniformly in all directions such the consistent stopping action is applied on all four wheels.

\section{Typical Disk Brake}

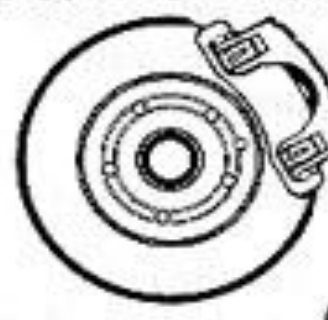

\section{Master Cyinder}

\section{Typical Drum Brake}

\section{Front Brakes}

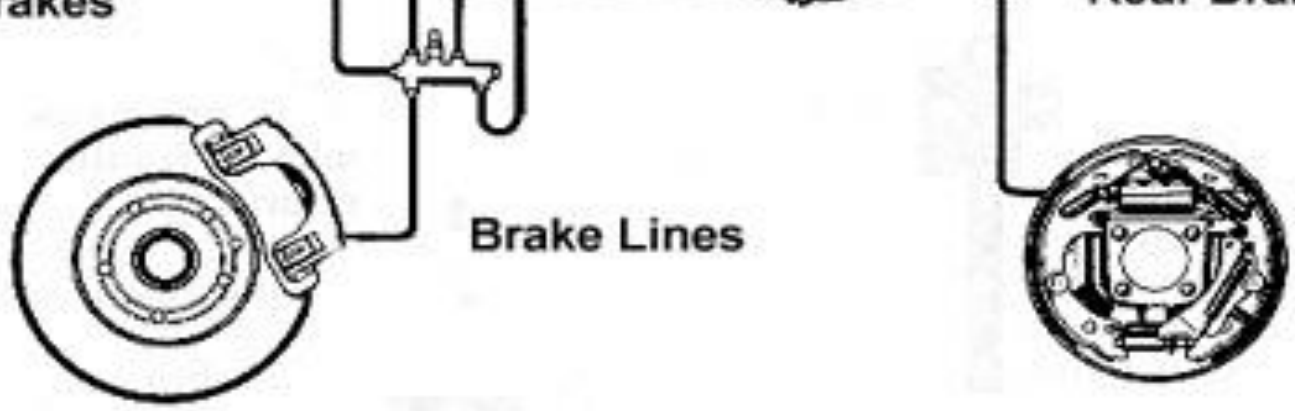

Fig. 6.6 Typical Automotive Braking System

\section{APPLICATION OF BRAKING}

As the brake lever is pressed to apply the brakes, the main engine piston pushes the brake fluid. This raises the fluid friction. This pressure is distributed to all pipes and to all wheel cylinders in keeping with Pascal's law. This added pressure pushes the two pistons out of the wheel cylinders. These pistons are mounted to the brake feet. Therefore, the brake shoes are widening towards the brake drums. Due to friction between the brake liners and the rim, the wheels are slowed down and the brakes are applied. There are disc brakes on the front wheels and drum brakes on the rear wheels of new vehicles.

\subsection{Brake Release}

As the pedal is pressed, the master cylinder piston returns to its original position due to the retractor mechanism installed in the master cylinder. As a consequence, fluid pressure decreases to its original value. The spring retractor given in the wheel cylinders pulls the brake shoes and the connection between the drum and the brake liners is broken. The brakes are then added. 
ICACCG2020 30-31 July, 2020, Ansal University, Gurgaon, India

International Journal of Technical Research \& Science (Special Issue)

\subsection{Prototype}

We have created a prototype of the device mentioned above. Here we used a dc battery instead of an electric car and a micro servo battery. The reports shall be as follows:

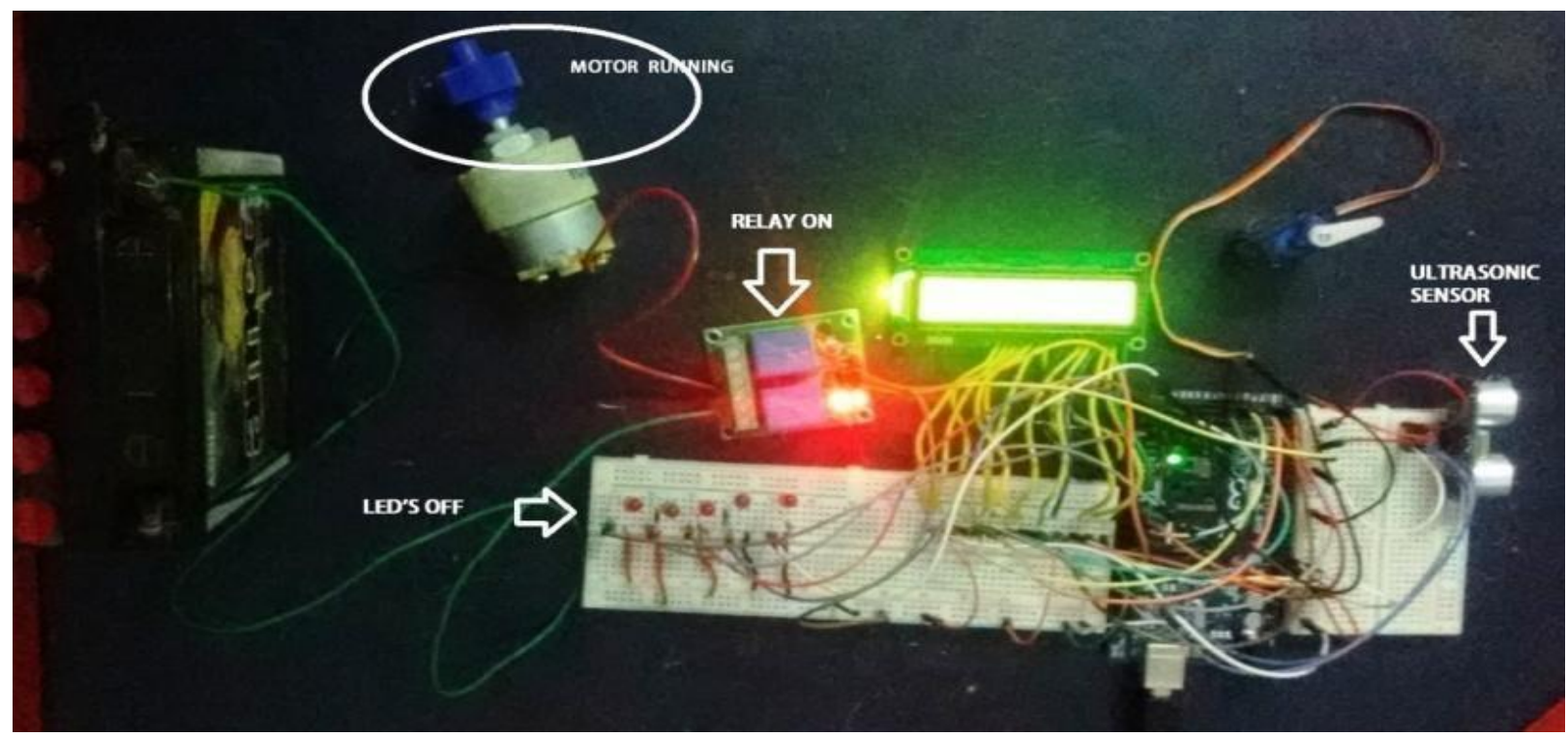

Fig. 7.1 Prototype Without Obstacle

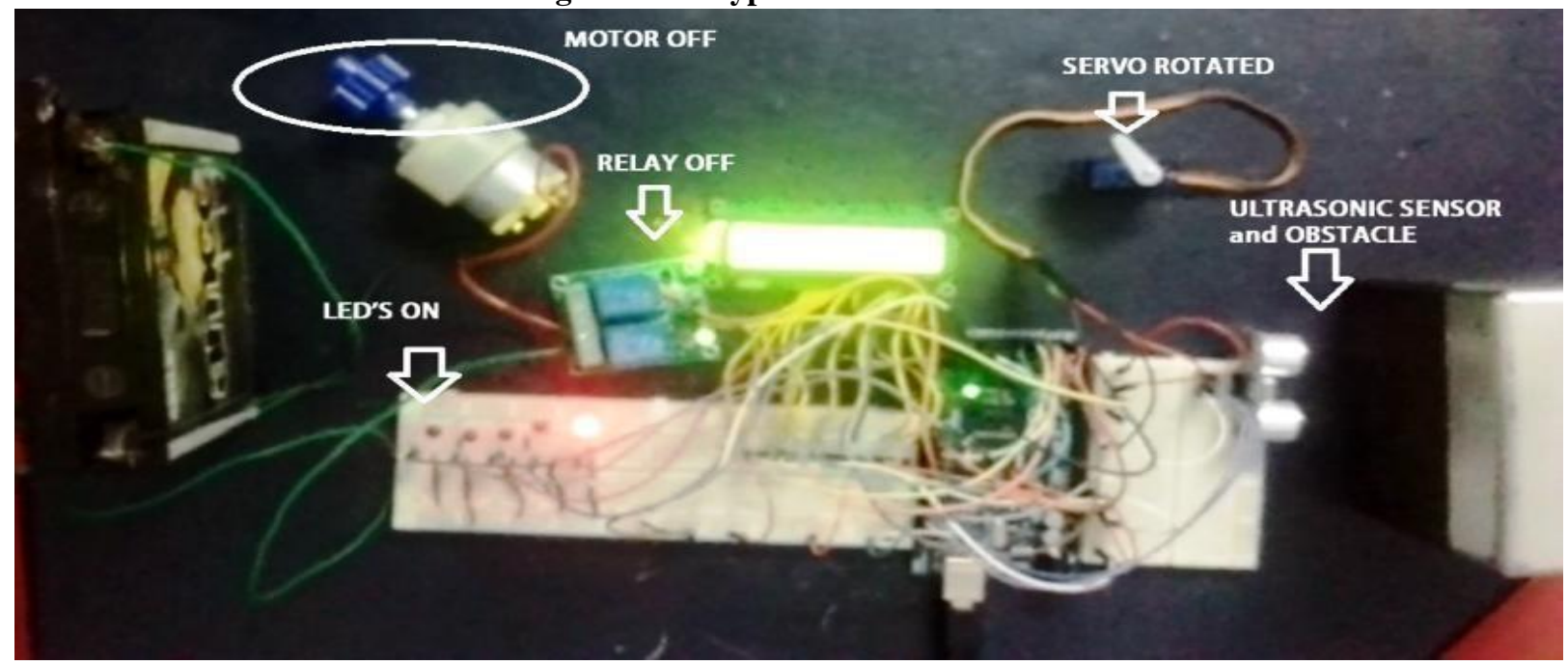

Fig. 7.2 Prototype with Obstacle

\section{CONCLUSION}

The automated collision warning system with the braking system provides substantial transport benefits in terms of protection, performance, affordability and accessibility and the environment in order to achieve its growth objectives. This aims to reduce the number of fatalities due to fatal injuries. Automatic crash detection with a braking mechanism is a complex large-scale control device, the architecture of which involved developments in sensor, actuator and communication technology and control system synthesis and analysis techniques. It is an indication of the advanced state of the art that these methods have achieved a level that could be widely used in this project. This system is very economical relative to the systems used in luxury vehicles. This cost-effective way of notification of crashes, along with automatic braking, can also be made applicable to low-cost vehicles, which can result in a major decrease in the death rate due to accidents.

\section{REFERENCES}

[1] Peden M, Scurfield R, Sleet D, 2004. "World Study on the Reduction of Road Traffic Accidents," Geneva: World Health Organisation, 2004.

[2] NASS Crashability Computer Program (2004). The Center for Information and Research of the National Highway Safety Administration.

[3] Najm, W. G., S. Basav, J. D. Smith, B. N. Campbell, guy. (2003).-Yes. Analysis of light vehicle collisions and pre-scratch situations based on the 2000 General Estimation Framework, NHTSA Scientific Report DOT HS 809573.

[4] Coelingh, E., H. Lind, W. Birk, D. Okay, Wetterberg (2006). FISITA World Congress, F2006V130, Yokohama Japan, Crash Warning with Auto Brake. 